\title{
N-PASS Versus mPAT in Assessment and Management of Neonatal Pain at Neonatal ICUs in Palestine
}

\author{
Khamis Elessi ${ }^{1}$, Shireen Abed ${ }^{2}$, Tayseer Afifi ${ }^{* 1}$, Rawan Utt $^{3}$, Mahmood Elblbessy ${ }^{1}$, Mohammed Obaid ${ }^{1}$, \\ Hassan Abu Elhatal ${ }^{1}$, Ahmed Elbhaisi ${ }^{1}$, Khaled Alsultan ${ }^{1}$, Mosab Samaan ${ }^{1}$, Rawnaq Mayadma ${ }^{4}$, Lama Badran ${ }^{4}$, \\ Anood Sawalha ${ }^{4}$, Hanan Rabaya'h ${ }^{4}$, Muna Musmar ${ }^{4}$, Juhina Hasassneh ${ }^{3}$, Aya Barham ${ }^{4}$, Sundus Shkokani ${ }^{3}$, \\ Alaa Rajabi ${ }^{3}$, Maysara Nakhla ${ }^{3}$, Mohammed Zedan ${ }^{5}$, Mohammed Abeid ${ }^{6}$ \\ ${ }^{1}$ Faculty of Medicine, The Islamic University-Gaza, Gaza, Palestine, ${ }^{2}$ Nassr Pediatric Hospital, Ministry of Health, Gaza, \\ Palestine, ${ }^{3}$ Faculty of Medicine, Al-Quds University, Jerusalem, Palestine, ${ }^{4}$ Faculty of Medicine, Al-Najah University, \\ Nablus, Palestine, ${ }^{5}$ Rafidia Hospital, Ministry of Health, Nablus, Palestine, ${ }^{6}$ Arabic Specialty Hospital, Al-Najah
} University, Nablus, Palestine

*Address of Correspondence: Tayseer Afifi; afifi.tayseer@gmail.com

Received 17 June 2019;

Accepted 29 June 2019;

Published 06 July 2019

\begin{abstract}
Background: Neonates frequently experience pain as a result of diagnostic or therapeutic interventions or as a result of a disease process. Neonates cannot verbalize their pain experience and depend on others to recognize, assess and manage their pain. Neonates may suffer immediate or long-term consequences of unrelieved pain. Accurate assessment of pain is essential to provide adequate management. Observational scales, which include physiological and behavioral responses to pain, are available to aid consistent pain management. Pain assessment is considered as the fifth vital sign. Objectives: Aims of the present study were (1) to compare two commonly cited neonatal pain assessment tools, Neonatal Pain, Agitation and Sedation Scale (N-PASS) and modified Pain Assessment Tool (mPAT), with regard to their psychometric qualities, (2) to explore intuitive clinicians' ratings by relating them to the tools' items and (3) to ensure that neonates receive adequate pain control. Methods: Two coders applied both pain assessment tools to 850 neonates while undergoing a painful or a stressful procedure. Each neonate was assessed before, during and after the procedure. The evaluation before and after the procedure was done using NPASS, while pain score during the procedure was assessed by mPAT. Analyses of variances and regression analyses were used to investigate whether tools could discriminate between the procedures and whether tools' items were predictors of pain severity. Results: Internal consistency, reliability and validity were high for both assessment tools. N-PASS tool discriminated between painful and stressful situations better than mPAT. There was no relation between the age of neonate and the pain score. Moreover, P-value was statistically significant between mPAT score and post procedural assessment score as well as between pre and post procedural assessment scores. Conclusion: Both assessment tools performed equally well regarding physiologic parameters. However, N-PASS makes it possible to assess pain during sedation. It was noticed that gaps exist between practitioner knowledge and attitude regarding neonatal pain.
\end{abstract}

Keywords: Pain, assessment, neonates, Neonatal Pain, Agitation and Sedation Scale (N-PASS), modified Pain Assessment Tool (mPAT), Gaza Neonatal Network (GNN)

\section{Introduction}

The need to assess and treat neonatal pain has been increasingly appreciated. Although neonates were initially thought to have limited response to painful stimuli, it was demonstrated that the developmental immaturity of the central nervous system makes the neonate more likely to feel pain ${ }^{[1]}$. It was further proved that untreated pain can have long-lasting physiologic and neurodevelopmental consequences. These concerns have resulted in a significant emphasis on improving and optimizing the techniques of analgesia for neonates and infants.

Neonatal discomfort, stress, or pain may be associated with routine patient care (e.g., physical examination and diaper changes), moderately invasive care measures (e.g., suctioning, phlebotomy, and peripheral intravenous line placement), or more invasive procedures (e.g., chest tube placement and circumcision). 
Newborns, both term and preterm, experience pain and have the right to receive safe, efficient and effective pain relief ${ }^{[2]}$. Compared with adults, the newborn displays a hypersensitivity to sensory stimuli and as such, is more prone to pain and its consequences. Newborns cannot verbalize their pain and thus depend on others to recognize, assess and manage their pain.

Historically, pain prevention and control have been underutilized in neonates because of these misconceptions ${ }^{[3,4]}$ (1) the pain pathways in neonates are unmyelinated or otherwise immature and cannot transmit painful stimuli to the brain, (2) there is no alternative for verbal self-report, which remains the "gold standard" for conveying a subjective experience like pain, (3) pain perception is located only in the cortex, and thalamocortical connections must be fully developed in order to allow pain perception, (4) the human infant does not have the psychological context in order to identify any experiences as painful and this does not develop until two years or later and (5) newborn infants are at greater risk for developing the adverse effects of analgesic or sedative agents, or these drugs have adverse long-term effects on brain development and behavior.

There is no scientific evidence supporting these misconceptions. On the contrary, beginning in the 1980 s, accumulating evidence ${ }^{[5]}$ demonstrated that both preterm and term infants experience pain and stress in response to noxious stimuli. By the middle of the second trimester, the human fetus has a highly differentiated and functional sensory system. This system appears to transmit different sensory modalities, like pain, touch, or vibration sense, which are mediated by very different pathways and loci of sensory processing in the mature adult nervous system.

In 1987, authors Anand and Hickey described the potential mechanisms by which neonates could perceive pain and clearly dispelled the long-held medical myth that neonates were unable to experience pain $^{[6]}$. Since then, extensive studies conducted worldwide have documented the newborn's physiological, behavioral, and biochemical responses to painful procedures ${ }^{[7,8]}$.

Newborn infants experience pain just as older children and adolescents experience pain; however, clinicians' ability and approach to assessing and managing neonates is inadequate and controversial. Newborn infants experience acute measurable physiologic, behavioral, metabolic, and hormonal responses to pain $^{[9,10]}$. They also experience long-term effects, including negative effects on neurologic and behavioral development. This is because the experience of pain occurs during a critical time of neurologic maturation ${ }^{[10]}$. In fact, preterm infants have demonstrated an exaggerated acute response to pain and worse behavioral and sensory long-term outcomes when compared to term neonates ${ }^{[11,12]}$. Surmounting evidence demonstrates that controlling pain in the newborn period is beneficial, improving physiologic, behavioral, and hormonal outcomes ${ }^{[9,10]}$.

Care providers are expected to prevent any infant from experiencing pain if at all possible. Pain assessment is a necessary part of neonatal pain management, as an indication for initiating therapy, as well as assessing its effectiveness. It is challenging to detect and measure the intensity of pain in neonates because of their inability to communicate with care providers.

All newborns undergo at least one painful procedure during their first few days of life (newborn screening and sometimes heel lancing for bilirubin). The impact of pain and distress may have short (physiological and behavioral) and long-term consequences (increased or decreased behavioral responses to pain) ${ }^{[13]}$. Yet, pain in neonates has been under-recognized, under- treated and frequently not evaluated or reassessed ${ }^{[14]}$. Despite the vast body of literature supporting the recommendations for assessment and management of neonatal pain, practice remains inadequate and inconsistent.

The aims of the present paper are (1) to evaluate the performance of two pain assessment tools; N-PASS and mPAT, (2) to assess the efficacy of facilitated neonatal pain management including nonpharmacological methods, in reducing pain during various procedures and (3) to provide bedside health professionals practical information about identification, prevention and management of pain in the neonates.

\section{Methods}

\section{Study design and settings}

This study was carried out in five NICUs in Gaza Strip and 8 NICUs in West Bank. The study involved 850 patients admitted to NICUs during the period from August 15th to November 8th 2018.

We chose a clinically representative rather than a randomized controlled sample as the present study aimed to compare the performance of the two assessment tools under daily clinical routine practice.

Neonates with facial malformations, abnormal neurological state or altered tonicity were excluded from the study since the assessment tools depend mainly on facial expressions and posture of the neonate during assessment.

\section{Pain assessment}

A staff of medical students, intern doctors and residents were trained for one week on study protocol, tools and data collection techniques of the study. The data collection sheet contained two domains. These domains were basic information and assessment tools. Assessment was done using N-PASS (figure 1) and mPAT (figure 2) scales. In addition, some baseline information was also encompassed such as; demography, cause of hospitalization, painful procedure and sedation state. The data collection sheet was revised and modified after conducting a pilot study.

Each neonate was assessed before, during and after a painful procedure or a stressful situation. The evaluation before and after the procedure was done by NPASS, while pain score during the procedure was assessed via mPAT. Then, the intervention taken by doctors was documented. The assessment depended on observation of the following; posture and tone, cry, sleep pattern, facial expression, color and vital signs. In case the neonate was premature, the score is increased according to gestational age. We added 3,2 or 1 for less than 28 weeks, 28-31 weeks or 32-35 respectively.

\section{Choice of tools}

Both scales rely on behavioral state and vital signs measurements to assess the level of pain. However, they differ in neonatal status whether the neonate is sedated or not. N-PASS has the advantage of enabling us to assess sedated neonates and give more reliable scores than mPAT.

This study was proceeded by a clinical audit in which mPAT scale was introduced to health professionals in NICUs in Gaza Strip. The 
clinical audit spotted light on the level of knowledge and attitude of health professionals toward neonatal pain. Then, this study was designed to provide an appropriate, evidence-based tool to aid health professionals in their practice.

First, N-PASS: Neonatal Pain, Agitation and Sedation Scale was developed in response to the need for a clinically usable, consistent, age appropriate assessment. And documentation of methodology for ongoing infant pain and also sedation in the neonatal intensive care unit (NICU) of Ronald McDonald Children's Hospital of Loyola University Medical Center. The NPASS is comprised of two measurements, each of which uses five criteria: crying/irritability, behavioral state, facial expression, extremity tone and vital signs. The pain/agitation score is assessed through observation without intervention, with a score range from 0 to 10 , with 0 to 2 points available for each criterion. The sedation score is typically assessed for patients receiving sedating medications and requires stimulation, with a score range from -10 to 0 , with points of -2 to 0 assigned for each criterion.

Second, the mPAT is an observational scale designed to assess neonatal pain. The mPAT is a modification of the original Pain Assessment Tool (PAT) scale that was first developed and piloted on the Butterfly Ward by Hodgkinson, Bear, Thorn \& Blaricum (1994). The mPAT scale was modified by O'Sullivan, Rowley, Ellis, Faasse, \& Petrie (2016) and piloted at The National Women's Newborn Intensive Care Unit at Auckland City Hospital, New Zealand. It is a multidimensional pain assessment tool that was specifically designed for neonates undergoing surgical intervention ${ }^{[16]}$. The mPAT has been validated for surgical and non-surgical neonates, from 24 weeks gestation to full term, up to 6 months old. The mPAT scale focuses on behavioral and physiological responses to painful stimuli, and includes a nurse's perception indicator (figure 2).

\section{Operational definitions}

The following terms was defined by the neonatal pain control group of the Newborn Drug Development Initiative ${ }^{[15]}$. Neonate is the age under 28 days. Early neonate is the age up to 3-7 days, late neonate is the age after 3-7 days. Pain is an unpleasant somatic or visceral sensation associated with actual or potential tissue damage. While stress is considered as any disturbance of the dynamic equilibrium between an infant and his/her environment that results in a physiologic response by the infant. Stress or pain response is defined as the individual's physiologic response to pain or stress that is characterized primarily by changes in four domains (i.e., endocrine-metabolic, autonomic, immunologic, and/or behavioral responses). Analgesia is the absence or reduction of pain in the presence of stimuli that would normally be painful. On the other hand, reduction in the intensity and/or duration of pain is termed as pain control. Sedation is when the neonate is kept calm and put to sleep using a sedative drug. But when the neonate is very sedated, and not easily arousable or unarousable is called heavily sedated ${ }^{[16]}$.

\section{Statistical analysis}

The collected data were entered into Microsoft Excel. Data were analyzed by the SPSS version 23. Frequency distributions and percentages were computed for all the variables.

\section{Ethical consideration}

Ethical clearance was obtained from The Ministry of Health, State of Palestine. Verbal consent was gained form NICUs' heads to enable us to observe neonates during various procedures. Study objectives, data collection procedures, benefits and risks of the study, confidentiality, and anticipated use of the results were explained to research committee in the ministry in detail before executing our work.

\begin{tabular}{|c|c|c|c|c|c|}
\hline \multirow{2}{*}{$\begin{array}{c}\text { Assessment } \\
\text { Criteria }\end{array}$} & \multicolumn{2}{|c|}{ Sedation } & \multirow{2}{*}{$\begin{array}{c}\text { Normal } \\
0\end{array}$} & \multicolumn{2}{|c|}{ Pain / Agitation } \\
\hline & -2 & -1 & & 1 & 2 \\
\hline $\begin{array}{l}\text { Crying } \\
\text { Irritability }\end{array}$ & $\begin{array}{l}\text { No cry with } \\
\text { painful stimuli }\end{array}$ & $\begin{array}{l}\text { Moans or cries } \\
\text { minimally with } \\
\text { painful stimuli }\end{array}$ & $\begin{array}{l}\text { Appropriate } \\
\text { crying } \\
\text { Not irritable }\end{array}$ & $\begin{array}{l}\text { Irritable or crying at } \\
\text { intervals } \\
\text { Consolable }\end{array}$ & $\begin{array}{l}\text { High-pitched or } \\
\text { silent-continuous cry } \\
\text { Inconsolable }\end{array}$ \\
\hline $\begin{array}{l}\text { Behavior } \\
\text { State }\end{array}$ & $\begin{array}{l}\text { No arousal to any } \\
\text { stimuli } \\
\text { No spontaneous } \\
\text { movement }\end{array}$ & $\begin{array}{l}\text { Arouses minimally } \\
\text { to stimuli } \\
\text { Little spontaneous } \\
\text { movement } \\
\end{array}$ & $\begin{array}{l}\text { Appropriate for } \\
\text { gestational age }\end{array}$ & $\begin{array}{l}\text { Restless, squirming } \\
\text { Awakens frequently }\end{array}$ & $\begin{array}{l}\text { Arching, kicking } \\
\text { Constantly awake or } \\
\text { Arouses minimally / no } \\
\text { movement (not sedated) }\end{array}$ \\
\hline $\begin{array}{c}\text { Facial } \\
\text { Expression }\end{array}$ & $\begin{array}{l}\text { Mouth is lax } \\
\text { No expression }\end{array}$ & $\begin{array}{l}\text { Minimal expression } \\
\text { with stimuli }\end{array}$ & $\begin{array}{l}\text { Relaxed } \\
\text { Appropriate }\end{array}$ & $\begin{array}{l}\text { Any pain expression } \\
\text { intermittent }\end{array}$ & $\begin{array}{l}\text { Any pain expression } \\
\text { continual }\end{array}$ \\
\hline $\begin{array}{c}\text { Extremities } \\
\text { Tone }\end{array}$ & $\begin{array}{l}\text { No grasp } \\
\text { reflexes } \\
\text { Flaccid tone }\end{array}$ & $\begin{array}{l}\text { Weak grasp reflex } \\
\downarrow \text { muscle tone }\end{array}$ & $\begin{array}{l}\text { Relaxed hands } \\
\text { and feet } \\
\text { Normal tone }\end{array}$ & $\begin{array}{l}\text { Intermittent clenched } \\
\text { toes, fists or finger splay } \\
\text { Body is not tense }\end{array}$ & $\begin{array}{l}\text { Continual clenched toes, } \\
\text { fists, or finger splay } \\
\text { Body is tense }\end{array}$ \\
\hline $\begin{array}{l}\text { Vital Signs } \\
\mathrm{HR}, \mathrm{RR}, \mathrm{BP} \text {, } \\
\mathrm{SaO}_{2}\end{array}$ & $\begin{array}{l}\text { No variability } \\
\text { with stimuli } \\
\text { Hypoventilation } \\
\text { or apnea }\end{array}$ & $\begin{array}{l}\text { < } 10 \% \text { variability } \\
\text { from baseline } \\
\text { with stimuli }\end{array}$ & $\begin{array}{l}\text { Within baseline } \\
\text { or normal for } \\
\text { gestational age }\end{array}$ & $\begin{array}{l}\uparrow 10-20 \% \text { from baseline } \\
\mathrm{SaO}_{2} 76-85 \% \text { with } \\
\text { stimulation - quick } \uparrow\end{array}$ & $\begin{array}{l}\uparrow>20 \% \text { from baseline } \\
\mathrm{SaO}_{2} \leq 75 \% \text { with } \\
\text { stimulation - slow } \uparrow \\
\text { Out of sync with vent }\end{array}$ \\
\hline
\end{tabular}

Figure 1: Neonatal Pain, Agitation and Sedation Scale (N-PASS) ${ }^{[17]}$ 


\begin{tabular}{|c|c|c|c|}
\hline Parameters & 0 & 1 & 2 \\
\hline \multicolumn{4}{|c|}{ The modified Pain Assessment Tool (PAT) } \\
\hline \multirow{5}{*}{ Posture/tone } & Relaxed & Extended & Flexed and/or tense \\
\hline & Normal & Digits widespread & Fists clenched \\
\hline & Some flexion & Trunk rigid & Trunk guarded \\
\hline & & Limbs abducted & Limbs drawn to midline \\
\hline & & Shoulders raised off bed & Head/shoulders resist posturing \\
\hline \multirow[t]{6}{*}{ Cry } & No & Yes & Yes \\
\hline & & Consolable & When disturbed \\
\hline & & Can be settled & Does not settle after handling \\
\hline & & & Loud \\
\hline & & & Whimpering \\
\hline & & & Whining \\
\hline \multirow{6}{*}{ Sleep pattern } & Relaxed & Easily woken & Agitated or withdrawn \\
\hline & & & Wakes with startle \\
\hline & & & Restless \\
\hline & & & Squirming \\
\hline & & & No clear sleep/wake pattern \\
\hline & & & Eye aversion or "shut out" \\
\hline \multirow{4}{*}{ Expression } & Relaxed & Frown & Grimace \\
\hline & Normal & Shallow furrows & Deep furrows \\
\hline & & Eyes lightly closed & Eyes tightly closed \\
\hline & & & Pupils dilated \\
\hline Color & Pink, well perfused & Occasionally mottled or pale & $\begin{array}{l}\text { Pale/dusky/flushed } \\
\text { Palmar sweating }\end{array}$ \\
\hline \multirow[t]{2}{*}{ Respirations } & Normal baseline rate & Tachypnea & Apnea \\
\hline & & At rest & At rest/with handling \\
\hline \multirow[t]{2}{*}{ Heart rate } & Normal baseline rate & Tachycardia & Fluctuating \\
\hline & & At rest & Spontaneous/at rest \\
\hline $\begin{array}{l}\text { Oxygen } \\
\text { saturation }\end{array}$ & Normal & Fleeting desaturation & Desaturation with/without handling \\
\hline Blood pressure & Normal & Fluctuates with handling & Hypo-/hypertension at rest \\
\hline $\begin{array}{l}\text { Nurse } \\
\text { perception }\end{array}$ & No pain perceived by me & $\begin{array}{l}\text { I think the baby has pain only with } \\
\text { handling }\end{array}$ & I think the baby is in pain \\
\hline
\end{tabular}

Figure 2: modified Pain Assessment Tool (mPAT) ${ }^{[16]}$

\section{Results}

\section{Baseline characteristics}

Among the 850 observed neonates, $68 \%$ were males and the mean age was 8 days (figure $3 \mathrm{~A}$ and $3 \mathrm{~B}$ ). Most of neonates were admitted within the first 24-hours of life primarily due to prematurity which accounted for $33 \%$ of cases. Figure 4 demonstrates the main causes of neonatal admission, but there were some neonates admitted for more than one cause. The early neonatal period was the most critical period for admission. Respiratory Distress Syndrome (RDS) comes in the second place,

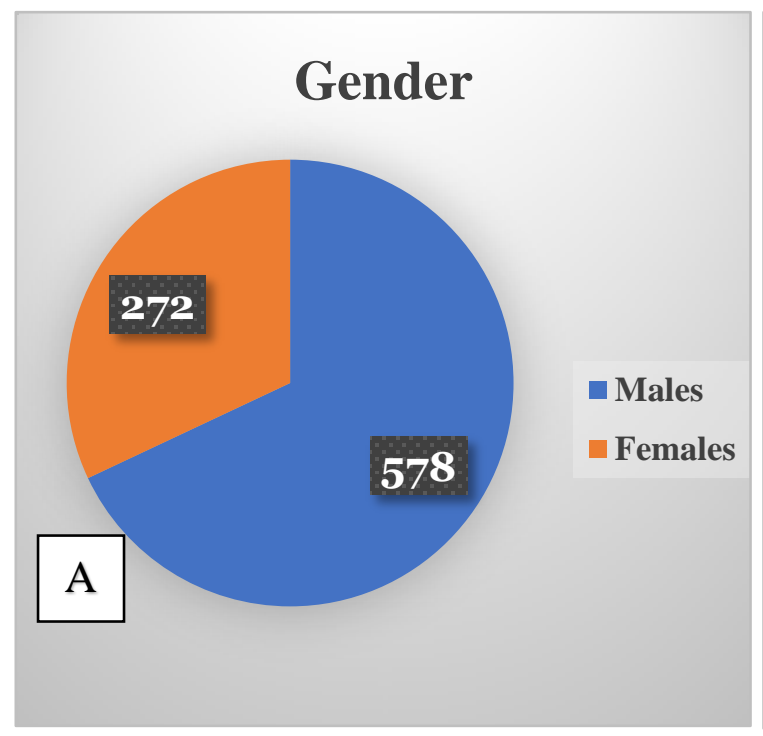

however most cases who suffered from RDS were premature. The other causes include causes such as acute bronchiolitis, feeding problems, dehydration, hydrocephalus and other medical conditions. Exposure to painful procedures was assessed by team members. These painful procedures illustrated in figure 5 varied in their intensity; some were daily routine procedures such as heal lancing and cannulation while others were invasive such as mechanical ventilation and lumbar puncture. The purpose of these procedure was diagnostic, therapeutic or surgical (figure 5). Some neonates were sedated at time of assessment due to invasive previous procedures. Nevertheless, only 106 neonates were sedated which accounts for only $12.5 \%$ of whole sample.

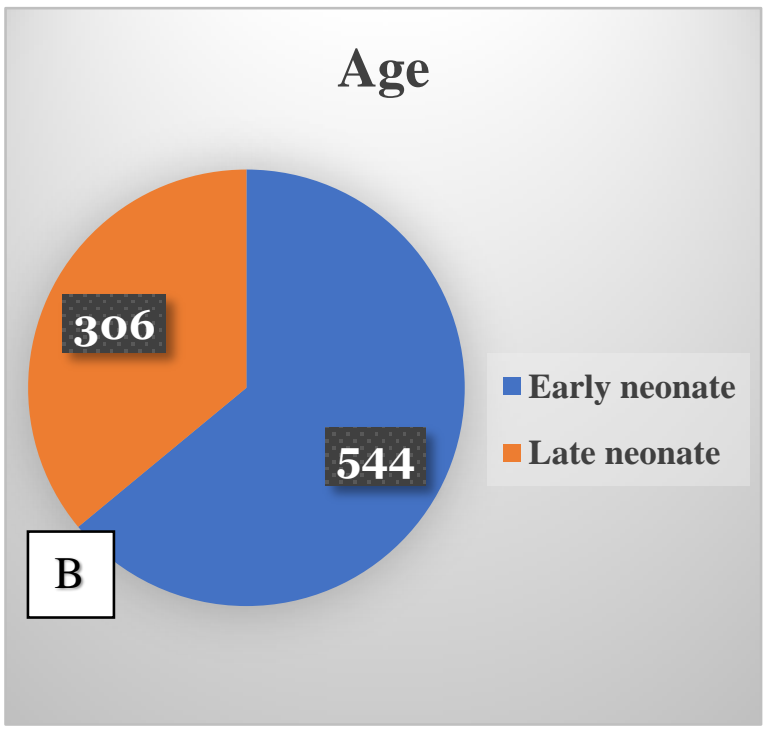

Figure 3A and 3B: Gender and Age distribution respectively 


\section{Cause of Hospitalization}

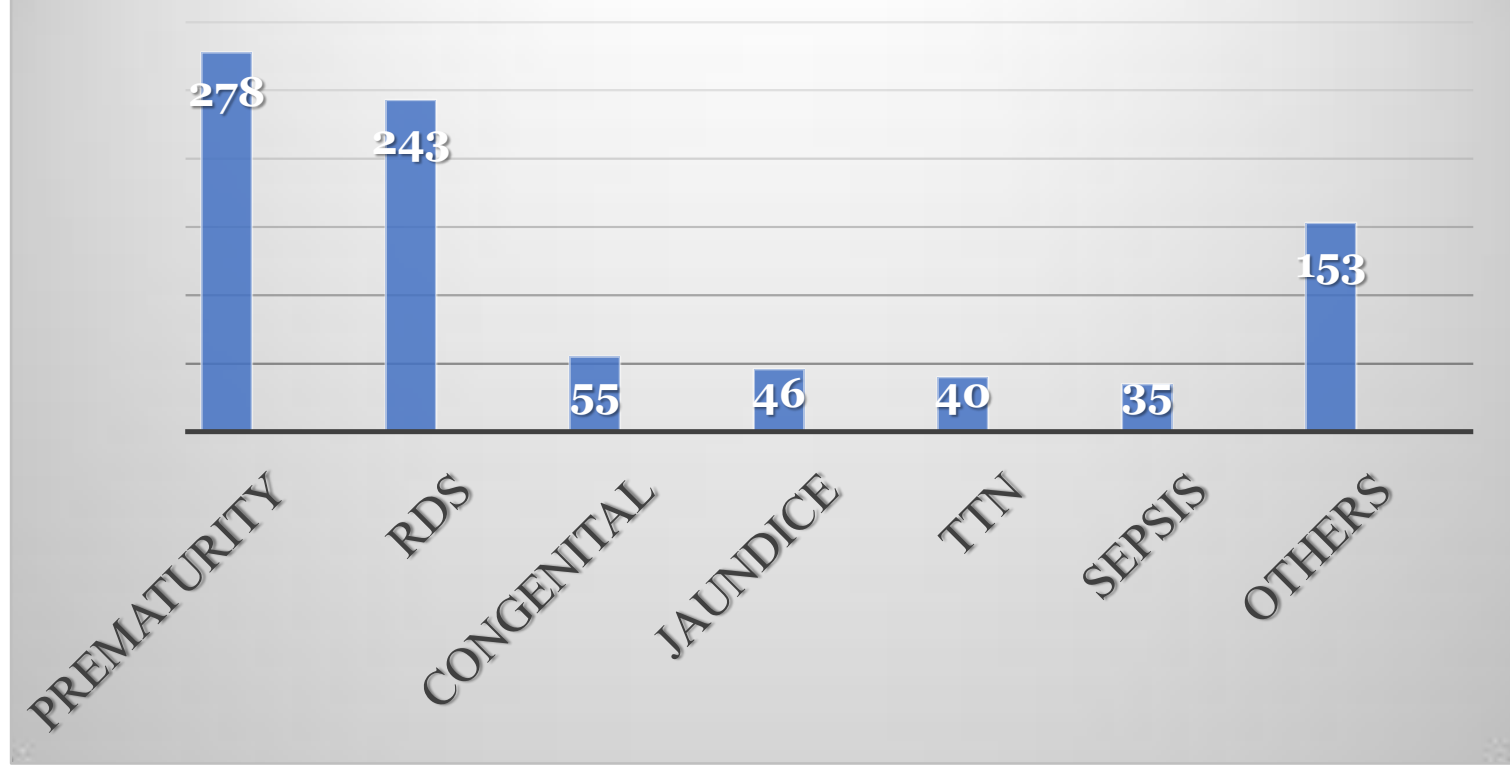

Figure 4: Causes of hospitalization distribution.

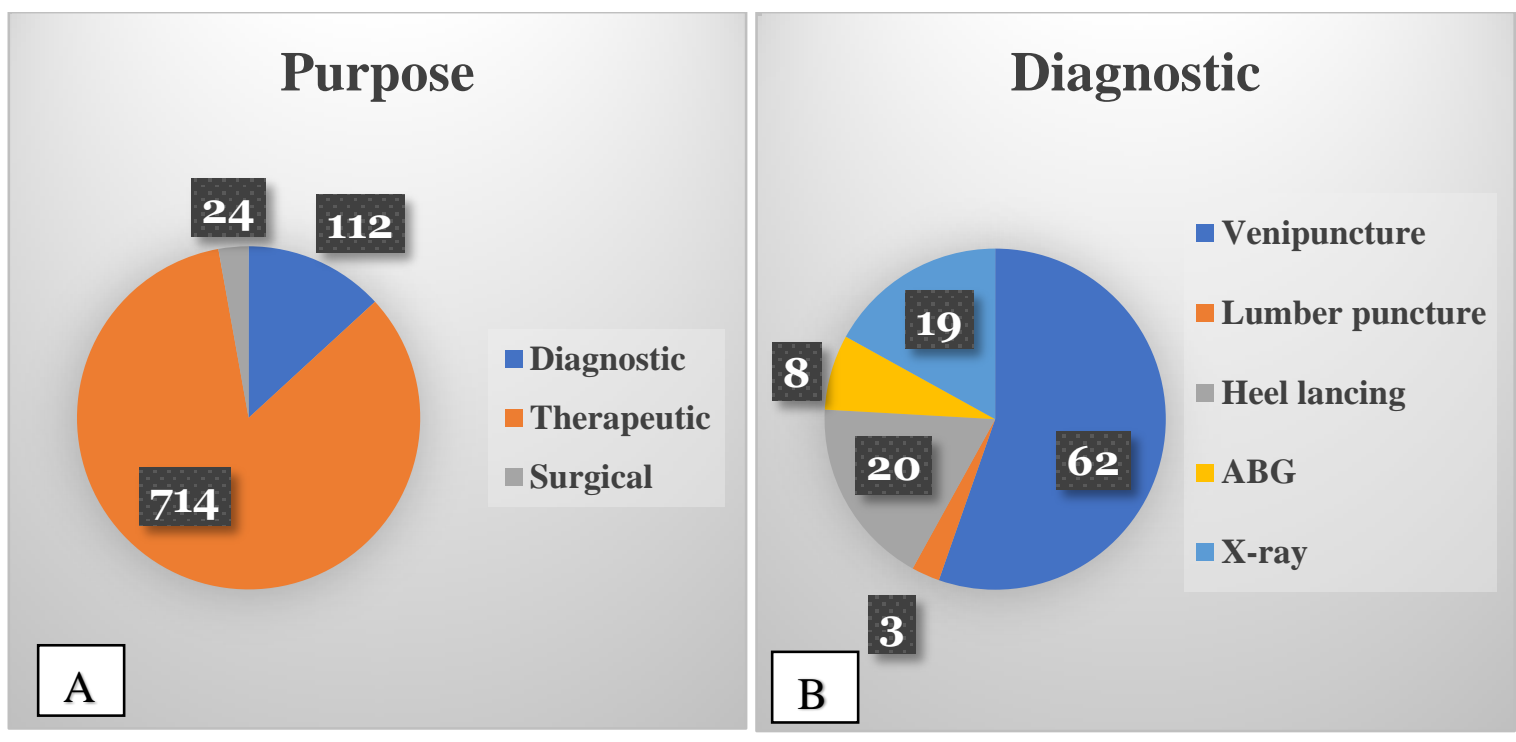

\section{Therapeutic}

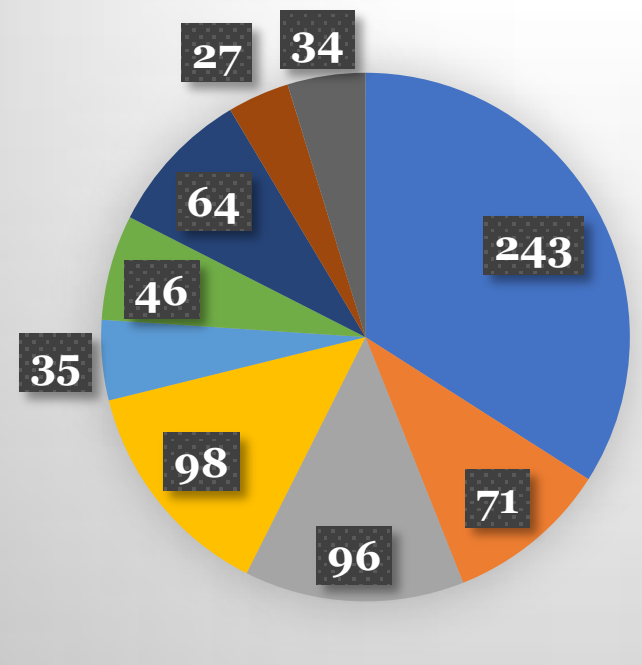

- Cannulation

Mechanical ventilation

Dressing change

IM injection

- Physiotherapy

Photo therapy

- NG tube

- Bladder catheterization

n Others

C 


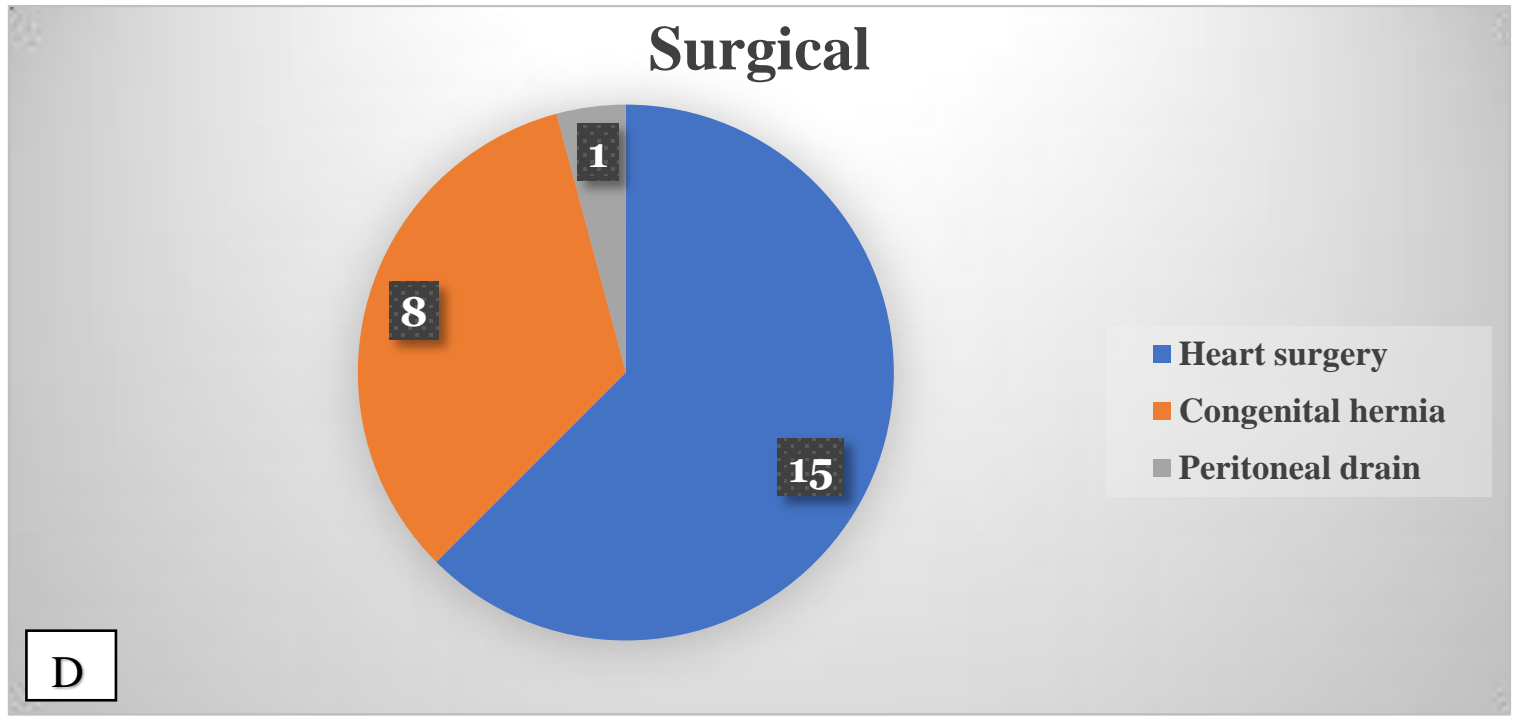

Figure 5: Classification of painful procedures according to purpose. (A) General classification. (B) Diagnostic procedures. (C) Therapeutic procedures. (D) Surgical procedures.

\section{Assessment by two tools}

Each neonate was assessed before and after the procedure by $\mathrm{N}$ PASS tool. Sedated neonates were assessed in minus as displayed in figure 1. In preprocedural assessment, all sedated neonates scored less than $0(n=106)$. While 93 neonates scored more than 5 which indicates that they were in marked stress. On the other hand, the rest of neonates scored between 0-5 which suggest the normal physiologic status of any neonate or mild feeling of pain. This assessment was done primarily as a reference point to compare the postprocedural assessment to it. This, in turn, allows us to evaluate the effectiveness of the intervention taken to reduce neonatal pain.
In order to decide the appropriate pain relief strategy whether to use medications or just nursing comfort measures (NCM), each neonate was assessed during the procedure using mPAT scale. Here, neonates experienced pain and started to show facial expressions and posturing change also their vital signs sometimes accelerate. The assessment results are shown in figure 6 .

The final step in assessment was evaluating the neonate after a while from the procedure. This was done using N-PASS tool. The aim of this step is to determine whether the intervention taken to reduce pain was effective in cases where needed. We noticed that there was a remarkable drop in post procedural assessment in scores where intervention was taken.

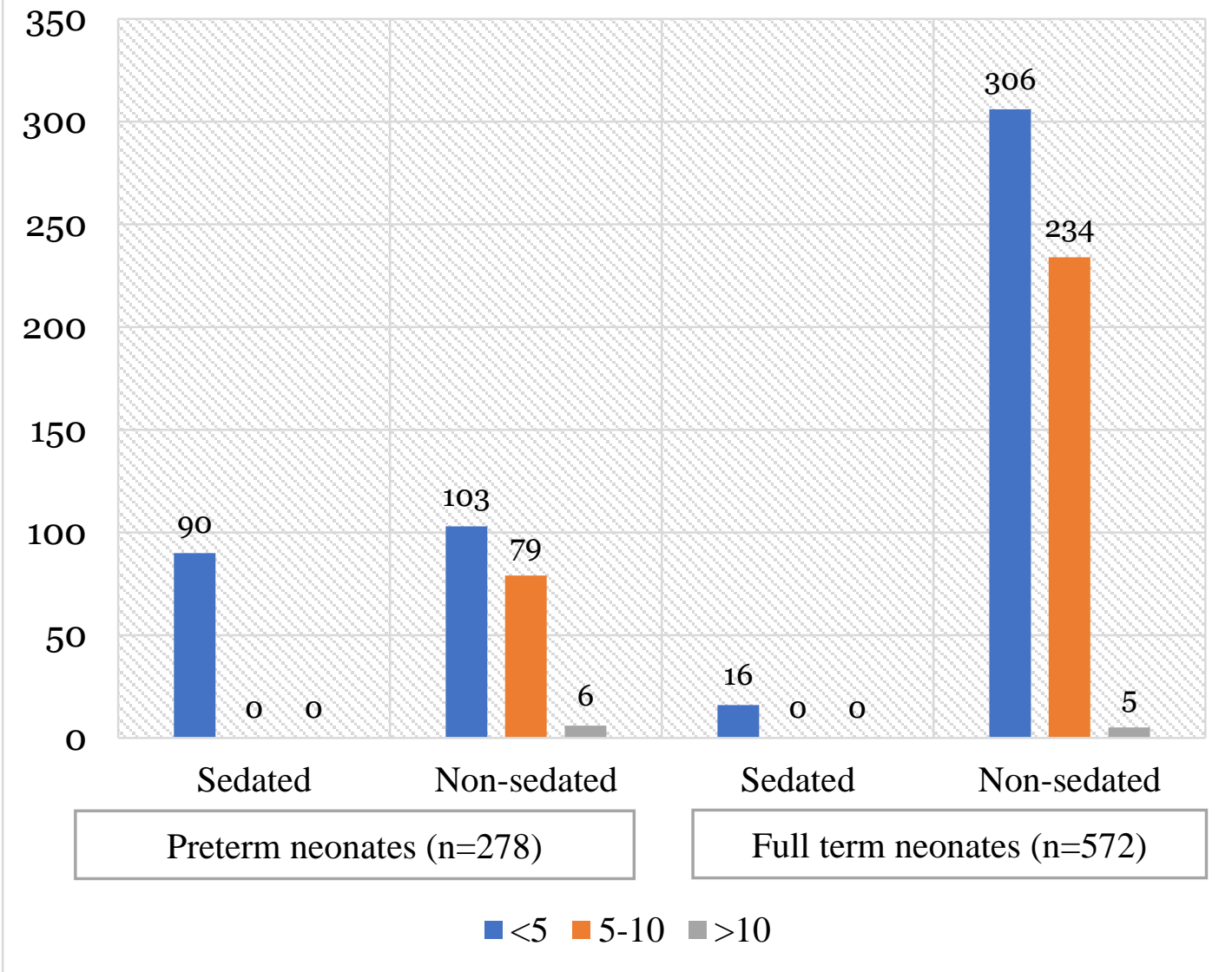

Figure 6: procedural assessment score by mPAT scale. 


\section{Intervention}

The type of intervention is to be NMCs, non-opioid analgesia or even the use of dose-adjustment opioids depends on mPAT score value which clarified in table 1 . However, clinical judgment and collaboration with the multidisciplinary team is advised ${ }^{[13]}$.

Table 1: Intervention guide based on mPAT score ${ }^{[16]}$

\begin{tabular}{cl}
\hline mPAT Score & Intervention \\
\hline$<\mathbf{5}$ & Nursing Comfort Measures (NCM) \\
$\mathbf{5 - 1 0}$ & $\begin{array}{l}\text { Paracetamol/Clonidine/Other Non-Opioid } \\
\text { Analgesia with NCM }\end{array}$ \\
$>\mathbf{1 0}$ & $\begin{array}{l}\text { Opioids with Non-Opioid Analgesia/Analgesia } \\
\text { Dose adjustment with NCM }\end{array}$ \\
\hline
\end{tabular}

Based on scores in figure 6 , most neonates scored less than 5 in which only NCMs are needed. However, it was found that, most not all, health professionals lack the enough knowledge about this approach. Thus, most neonates were left after completing the procedure. On the other hand, it was obvious that clinicians were informative regarding the use of analgesia and dose tittering to fit the neonate. As mentioned above, some neonates were sedated at time of assessment. Nevertheless, the use of sedation was reasonable and justified for the situation of the neonate. It is important to mention that sedated neonates require nothing to be done following the procedure.

We observed some gaps in the clinical practice in which the neonate was neglected after the procedure in case of less than 5 score. Interestingly, very few numbers of neonates received analgesia they didn't need. Furthermore, the results were remarkably different among centers. This mandates the presence of unified systemic approach for neonatal pain. Figure 7 summarizes the intervention taken for non-sedated neonates $(n=744)$ with regards to their mPAT score.

\section{Internal consistency}

Internal consistency, measured by Cronbach's alpha, for N-PASS tool was already calculated in the literature $(0.84 \text { to } 0.89)^{[18]}$ and was the same in our analysis (0.86) all items should be included in pain assessment for either sedated or non-sedated neonates. On the other hand, for mPAT scale, there are no studies that report the internal consistency of the scale. We did the assessment after a pilot study in which we found that our setting lacks the measurement of blood pressure and there is no nurse perception. So, we deleted the last two items of the original scale so as to suit our practices in the NICUs. We got 0.76 Cronbach's alpha for mPAT. However, if we remove the respiration assessment from the scale, it will reach 0.81 .

\section{Statistical relationships}

There was no statistical significance between age of neonate and the pain score in either pain assessment scales. Which supports the fact that neonates feel pain or at least they are alert to stressful stimuli regardless of their age. Moreover, P-value was statistically significant between mPAT score and post procedural assessment score $(\mathrm{P}=0.038)$ as well as between pre and post procedural assessment scores $(\mathrm{P}=0.01)$. This means that the neonatal state differs from the preprocedural period and postprocedural period. Thus, this behavioral change proves the presence of pain sensation in neonates. As displayed in figure 7, scores were higher for both tools in full-term neonates than preterm.

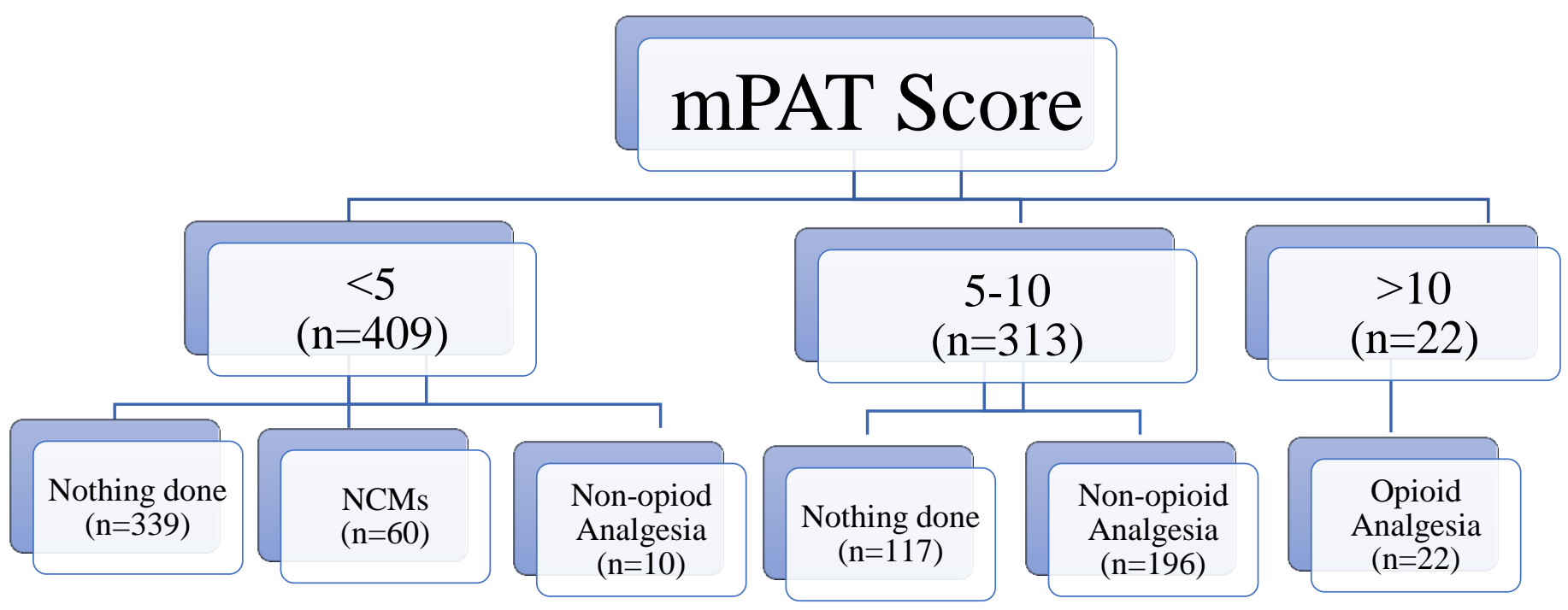

Figure 7: Intervention taken by health professionals to relieve pain. 


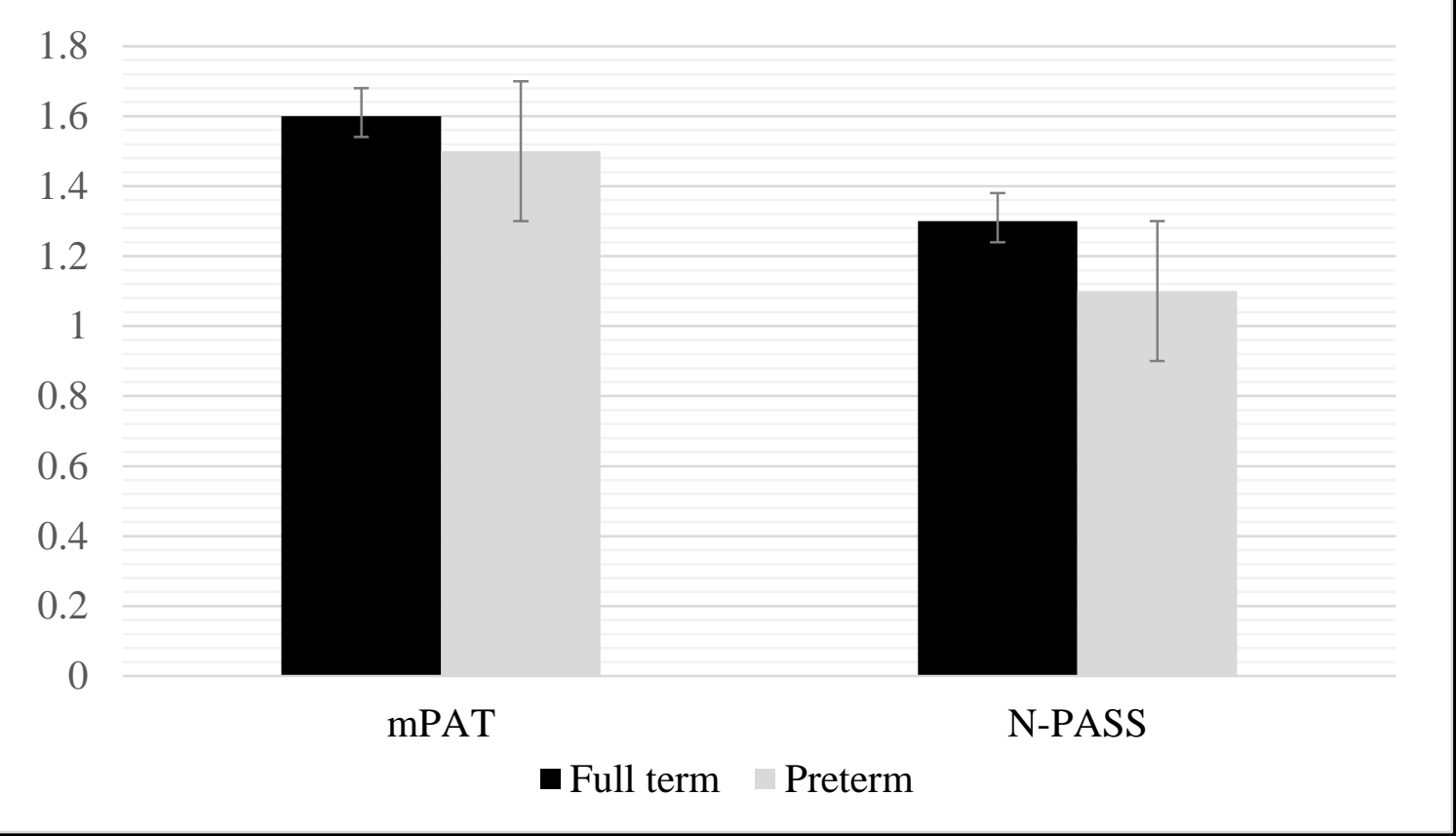

Figure 8: Means and standard errors for pre- and full-term neonates in painful situations.

\section{Discussion}

Neonatal pain never fails to raise controversial among health professionals. Previous thoughts were that neonates do not feel pain. However, after correction these concepts and introducing many pain assessment tools, it becomes more convenient. To the best of our knowledge, this is the first prospective, multicenter study in Palestine concerning neonatal pain. This study was preceded by a clinical audit, conducted by the same team, in which clinical practice gaps and knowledge deficits were identified. Then, the team worked on introducing a reliable tool for clinicians to use in their practice. Thus, this was the aim of this study, in addition to validate these tools for literature.

Both tools attained good internal consistency indicating that they are homogeneous. However, mPAT tool has not been tested in preterm neonates yet. Thus, the internal consistency score for preterm neonates in mPAT is the same as all neonates.

We noticed a remarkable discrepancy in regards to pain management among all NICUs. Some units used pharmacological and non-pharmacological interventions, while other units didn't attempt to do anything for neonates. This can occur for several reasons and the researchers explain it by lack of culture of nonpharmacological approach and family involvement in some situations. NCMs are of great value in pain relief whether they are applied isolated or as complementary measures to pharmacological treatment ${ }^{[19]}$. Nonpharmacologic approaches are generally more effective when used in combination than when used alone. Some studies found that health professionals prefer the pharmacological treatment which also can be explained by the lack of knowledge of NCMs role in comforting neonates ${ }^{[20]}$. This would be a potential field for nursing training and implementation in our settings. Furthermore, inter-professional trust and support for evidencebased practice in a prominent barrier in the use of pharmacological intervention for pain relief. As some professionals still argue about neonatal pain issue and report that medications might have some considerable side effects on neonatal liver and kidneys.
It is interesting to stress that although admitting that some procedures were very painful, our assessment revealed low scores in nearly all neonates exposed to such procedures. This might be explained by the skillful practice of health professionals as the analgesia use is underutilized. We found similar results in the following articles ${ }^{[21,22]}$ in which invasive painful procedures were performed without analgesia. Thus, there must be a collaboration between health professionals and researches to explain this phenomenon.

Health professionals used to depend mainly on crying and facial expressions to recognize to neonatal pain. But neonatal pain assessment tools contain other items such as vital signs as parameters. This is very essential especially in cases where neonates are sedated. Since in such cases the observer won't be able to assess pain or stress. It was noticed that vital signs change markedly when performing procedures on sedated neonates. So, crying and facial expressions should not be considered alone to intervene as they occur in various nonpainful situations.

One of the reasons that may have contributed to the absence of assessment scales in Palestinian NICUs is that at present time there are no single clinical tool is recommended as the gold standard superior to all others ${ }^{[23,24]}$. In addition, health professionals are concerned with the use of opioids and their effects on neonates. A study conducted in two Austrian units in which the implementation of a pain management protocol based on the N-PASS scale led to an increase in the use of opioid drugs ${ }^{[25]}$.

As both tools have pretty equal internal consistency and validity, including discriminant validity, no tool can be recommended in favor of the other. However, N-PASS tool includes assessment values for sedated neonates and considers the gestational age in the final score. On the other hand, mPAT is more reliable for choosing appropriate intervention.

It is clear that several scoring tools have been developed, the use of a single assessment tool to address all the needs for neonates is not advisable as each tool was developed and validated for selected populations and clinical settings. The choice of the pain assessment 
tool is dependent upon the neonatal population to be assessed, and the different types of pain that need to be evaluated. Thus, we recommend the use of a combination of both tools in clinical practice. This will give health care professionals the advantage of assessing during sedation. Moreover, it will guide the choice of pain control strategy.

\section{Conclusion}

Neonates feel pain regardless of their age. They experience pain in a similar manner to older children and adults. Pain is most common and intense in infants who are cared for in the neonatal intensive care unit (NICU). It was noticed that, in cases where interventions were not taken, the post procedural assessment was higher than the pre-procedural one. Sedation masks the feeling of pain, but does not necessarily reduce it. mPAT score is reliable in determining the choice of pain reduction strategy. However, it is not accurate in assessment of preterm or sedated neonates. NPASS score provides better degree of accuracy in assessment of preterm as well as sedated neonates. Nevertheless, gaps still exist between knowledge and attitude regarding the assessment and management of neonatal pain. Staff awareness is warranted and establishment of a national guideline for neonatal pain management is promising. Finally, the two assessment tools applied in the present study are comparable with reference to their validity and reliability and both are quite easily used in daily clinical work. But, a combination between both of them is required for best practice in assessment and management of neonatal pain in our settings.

\section{Competing Interest}

Authors declare that they have no competing interests.

\section{Authors' Contribution}

Afifi $\mathrm{T}$ and Elessi K prepared the study design. Abed $\mathrm{S}$ conducted the pilot study and made some changes on assessment strategy. Afifi T, Utt R, Elblbessy M, Obeid M, Abu Elhatel H, Elbhaisi A, Alsultan K, Mayadma R, Badran L, Sawalha A, Rabaya'h H, Musmar M, Hasassneh J, Barham A, Shkokani S and Nakla M collected the data, assessed neonatal pain and entered data to SPSS. Afifi $\mathrm{T}$ and Samaan M analyzed the data. Abed S supervised Gaza Strip team. Zedan M and Abedi M supervised West Bank team. Afifi $\mathrm{T}$ wrote the initial draft. Abed $\mathrm{S}$ and Utt $\mathrm{R}$ revised the draft and made some editing. Afifi $\mathrm{T}$ prepared the final draft. Samaan $\mathrm{M}$ revised the statistics and figures of the final draft. Elessi $\mathrm{K}$ supervised the whole study. All authors approved the final draft of the study.

\section{Acknowledgment}

The authors wish to thank all NICU team, doctors and nurses, in the neonatal units included in this study for their continuous help and support.

\section{Funding}

None

\section{Availability of Data and Materials}

The datasets used and/or analyzed during the current study are available from the corresponding author on reasonable request.

\section{Significance}

Neonatal pain becomes of great concern after correction of previous misconceptions and understanding of neonatal pain consequences. So, it is now well recognized that newborns feel pain as anyone other. However, the limitation of non-verbal expression of pain in neonates still exist. On the other hand, multidimensional pain scales have been developed and introduced to health care providers. As a result, it becomes now easier to evaluate and manage neonatal pain. On the contrary, the local guidelines, here in Palestine, lack the enough information and details on this topic. Thus, and after counseling Gaza Neonatal Network, it was decided to conduct this study about neonatal pain.

\section{References}

[1] Tarun Bhalla, Ed Shepherd and Joseph D. Tobias. Neonatal Pain Management. Saudi J Anaesth. 2014 Nov; 8(Suppl 1): S89-S97. doi: [10.4103/1658-354X.144085]

[2] Declaration of Montreal. International Association for the study of pain 2014 August 6

[3] Anand KJ, Hickey PR. Pain and its effects in the human neonate and fetus. N Engl J Med 1987; 317:1321.

[4] Anand KJ, Brown MJ, Causon RC, et al. Can the human neonate mount an endocrine and metabolic response to surgery? J Pediatr Surg 1985; 20:41.

[5] Andrews K, Fitzgerald M. Cutaneous flexion reflex in human neonates: a quantitative study of threshold and stimulus-response characteristics after single and repeated stimuli. Dev Med Child Neurol 1999; 41:696.

[6] Anand KJ, Hickey PR. Pain and its effects in the human neonate and fetus. $\mathrm{N}$ Engl J Med 1987 Nov 19;317(21):1321-9.

[7] Spence K, Henderson-Smart D, New K, Evans C, Whitelaw J, Woolnough R, et al. Evidenced-based clinical practice guideline for management of newborn pain. J Paediatr Child Health 2010 Apr;46(4):184-92.

[8] Assessment and management of pain. Registered Nursing Association of Ontario 2013 December 2013( $\left.3^{\text {rd }}\right)$

[9] Lago P, Garetti E, Merazzi D, et al. Guidelines for procedural pain in the newborn. Acta Paediatr (Oslo, Norway: 1992). 2009;98(6):932-9. doi:10.1111/j.16512227.2009.01291.x. A foundational systematic review of procedural pain prevention and treatment of NICU neonatal patients.

[10] Anand KJ, Aranda JV, Berde CB, et al. Summary proceedings from the neonatal pain-control group. Pediatrics. 2006;117(3 Pt 2):S9-S22.

[11] Frunau RVE. Long-term consequences of pain in human neonates. In: Anand JKS, Stevens BJ, McGrath PJ, editors. Pain in neonates. 3. Amsterdam: Elsevier; 2007. pp. 55-76.

[12] Peterson BS, Vohr B, Staib LH, Cannistraci CJ, DOlberg $\mathrm{A}$, Schenier $\mathrm{KC}$, et al. Regional brain volume abnormalities and long-term cognitive outcome in preterm infants. JAMA. 2000;284:1939-1947. doi: 10.1001/jama.284.15.1939.

[13] Stevens BJ, Pillai RR, Oberlander TF, Gibbins S. Assessment of pain in neonates and infants. Pain in neonates and infants 2007(3rd):67-90. 
[14] Johnston C, Barrington KJ, Taddio A, Carbajal R, Filion F. Pain in Canadian NICUs: have we improved over the past 12 years? Clin J Pain 2011 Mar;27(3):225-32.

[15] Anand KJ, Aranda JV, Berde CB, et al. Summary proceedings from the neonatal pain-control group. Pediatrics 2006; 117:S9.

[16] Australia and New Zealand Collage of Anesthetics and Faculty of Pain Medicine (ANZCA). (2015) Acute pain management: Scientific Evidence, fourth edition, pp 413414

[17] Patricia A. Hummel, Mary L. Puchalski, Steven D. Creech, Marc G. Weiss. N-PASS: Neonatal Pain, Agitation and Sedation Scale - Reliability and Validity. Vol. 2, N. 6, November 2004

[18] Hummel P, Lawlor-Klean P, Weiss MG. Validity and reliability of the N-PASS assessment tool with acute pain. Journal of Perinatol. 2010 Jul;30(7):474-8. doi: 10.1038/jp.2009.185. Epub 2009 Nov 19.

[19] Harrison D, Bueno M, Reszel J. Prevention and management of pain and stress in the neonate. Res Rep Neonatal. 2015;5:9-16. doi: 10.2147/RRN.S52378.
[20] Khoza SL, Tjale AA. Knowledge, attitudes and practices of neonatal staff concerning neonatal pain management. Curationis. 2014 Nov 28;37(2):E1-9. doi: 10.4102/curationis.v37i2.1246.

[21] Porter FL, Wolf CM, Gold J, et al. Pain and pain management in newborn infants: a survey of physicians and nurses. Pediatrics. 1997;100(4):626-32.

[22] Carbajal R, Roussef A, Danan C, et al. Epidemiology and treatment of painful procedures in neonates in intensive care units. JAMA. 2008;300(1):60-70.

[23] M. Ranger, C.C. Johnston, K.J.S. Anand. Current controversies regarding pain assessment in neonates. Semin Perinatol, 31 (2007), pp. 283-288.

[24] K.J.S. Anand. Pain assessment in preterm neonates. Pediatrics, 119 (2007), pp. 605-607

[25] P. Deindl, L. Unterasinger, G. Kappler, T. Werther, C. Czaba, V. Giordano, et al. Successful implementation of a neonatal pain and sedation protocol at 2 NICUs. Pediatrics, 132 (2013), pp. e211-e218. 